\title{
Routine preoperative chest radiography in non-cardiopulmonary surgery
}

\author{
A M REES, C J ROBERTS, A S BLIGH, K T EVANS
}

British Medical fournal, 1976, 1, 1333-1335

\section{Summary}

Preoperative radiography was performed on 667 consecutive patients undergoing elective non-cardiopulmonary surgery in a large hospital in Wales. Of all significant findings reported $54 \%$ were due to cardiomegaly and $19 \%$ to chronic respiratory disease, and no appreciable abnormality was found in any patient under 30 . Out of a subsample of 152 examined prospectively, $38 \%$ had received a chest radiograph within the last year, and the maximum marrow dose had been exceeded in $12.5 \%$. It is concluded that the procedure, as presently practised, is not only being considerably overused but is also exposing many recipients to the potentially harmful effects of over-irradiation. The findings provide further evidence in support of the Royal College of Radiologists' proposal that a national multicentre study of diagnostic radiology should be set up with some urgency.

\section{Introduction}

Over the last 20 years the chest radiograph has become a routine part of assessing the patient before general anaesthesia. ${ }^{1} \mathrm{~A}$ policy such as this has much in common with, for example, one which advocates that all women over 30 should undergo cervical cytology or that all those employed in hazardous occupations should receive regular examination. Many clinicians now consider the chest radiograph to be an extension of the routine clinical examination rather than a specialised procedure to be used in specific instances. In the context of preoperative management in non-cardiopulmonary surgery, the original concept of the function of diagnostic radiology - that is, as an adjunct to clinical diagnosis-appears to have changed, and there is good reason for believing that it has now become a routine national screening, rather than a selected individual clinical, service.

The growth of diagnostic radiological services in England and Wales has occurred unevenly, and in 1968 various criteria of use (such as inpatient units of radiology per thousand discharges and deaths) showed an almost twofold variation between hospital regions. According to Ashley et al, ${ }^{2}$ the growth of these services has been generated by the "scientific staff themselves; partly by fashion; and to some extent in accordance with local interests."

Departments of Community Medicine and Diagnostic Radiology, Welsh National School of Medicine, Cardiff CF4 4XN

A M REES, BSC, medical student

C J ROBERTS, MD, PHD, senior lecturer

A S BLIGH, MB, FRCR, consultant radiologist

K T EVANS, FRCR, FRCP, professor of radiology
In 1974, in one area health authority in Wales, some 45000 people $(16 \%$ of the population of the area) underwent radiography and, of these, some 4000 received a preoperative chest radiograph. In the USA radiographic examination of the chest comprises $45^{\circ}$ of all the diagnostic radiological procedures which are undertaken. ${ }^{3}$

Recently, the value of, and the criteria for, performing routinely such investigations as skull radiography after acute trauma in childhood ${ }^{4}$; neurological radiography ${ }^{5}$; routine chest radiography in children and adolescents ${ }^{6}$; preoperative chest radiography $^{1}$; intravenous urography ${ }^{7}$; routine screening and lateral chest radiographs in a hospital-based population ${ }^{3}$; and diagnostic radiology in casualty departments ${ }^{8}$ have been questioned. Such studies have been prompted, not only by the increasing numbers of requests but also by a lack of information on the reasons for these investigations and on the extent of their influence on subsequent management of the patient. Our purpose is to make a tentative approach to these considerations and hence to the problem of deciding whether the cost of this form of screening service is acceptable in relation to its estimated benefit.

\section{Material and methods}

We studied 667 consecutive patients undergoing elective non-acute non-cardiopulmonary surgery in a large hospital in Wales. Information on the age, sex, type of operation performed, $x$-ray findings, and name of reporting radiologist was obtained retrospectively for 515 patients. Similar information, supplemented by data on smoking habits, period since last radiograph, and answers to a standardised questionnaire covering previous history of chronic bronchitis, ${ }^{9}$ grade III dyspnoea, ${ }^{9}$ myocardial infarction, ${ }^{10}$ angina, ${ }^{10}$ hypertension, and tuberculosis was collected prospectively for a further 152 new patients.

Abnormal radiographic findings were classified under six headings - those of the heart, aorta and pulmonary artery, lung fields, pleura, skeletal system, and mediastinum. Within each, the abnormalities discovered were allocated into "significant" and "non-significant" categories with reference to their relevance to general anaesthesia and surgery.

\section{Results}

There were 126 significant and 173 non-significant abnormalities reported (table I). Of 60 significant findings in males, $27(45 \%)$ were cardiomegaly and $10(17 \%)$ were chronic obstructive airways disease (COAD), and of the 66 significant findings in females $41(62 \%)$ were cardiomegaly and $7(11 \%)$ COAD. The total abnormality yield by age and sex is shown in table II. No abnormalities of either category were detected below 20 years of age, and no significant changes under 30 . In the 20-29 age group two cases classed as abnormal were in the non-significant category. The most significant abnormality was cardiomegaly without specific chamber enlargement-in women this showed a particularly steep climb with age compared with that in men. 
TABLE I-Abnormalities reported in 667 patients

\begin{tabular}{|c|c|c|}
\hline & $\begin{array}{c}\text { Significant } \\
\text { abnormalities } \\
\text { (and No of patients) }\end{array}$ & $\begin{array}{c}\text { Non-significant } \\
\text { abnormalities } \\
\text { (and No of patients) }\end{array}$ \\
\hline Heart & $\begin{array}{l}\text { Cardiomegaly ( } 68) \\
\text { Left ventricle enlarged (18) }\end{array}$ & \\
\hline $\begin{array}{l}\text { Aorta and } \\
\text { pulmonary artery }\end{array}$ & Enlarged pulmonary artery (1) & $\begin{array}{l}\text { Unfolded aorta (72) } \\
\text { Right-sided aorta (1) }\end{array}$ \\
\hline Lung field & $\begin{array}{l}\text { Chronic obstructive airways } \\
\text { disease (17) } \\
\text { Collapse (5) } \\
\text { Metastases (4) } \\
\text { Asbestosis (1) } \\
\text { Fibrosis (2) } \\
\text { Pulmonary infarction (1) } \\
\text { Complicated } \\
\text { pneumoconiosis (2) }\end{array}$ & $\begin{array}{l}\text { Old tuberculosis (41) } \\
\text { Simple pneumoconiosis (13) }\end{array}$ \\
\hline Pleura & $\begin{array}{l}\text { Effusion (1) } \\
\text { Asbestotic plaques (1) }\end{array}$ & Thickening (9) \\
\hline Skeletal & $\begin{array}{l}\text { Metastases (2) } \\
\text { Cervical spondylosis (1) }\end{array}$ & $\begin{array}{l}\text { Kyphosis and scoliosis (8) } \\
\text { Old fractures (10) } \\
\text { Enchondromata (1) } \\
\text { Disc degeneration (4) } \\
\text { Old rib operations (2) } \\
\text { Pectus excavatum (2) } \\
\text { Congenital rib anomalies (6) } \\
\text { Arthritides (shoulder) (3) }\end{array}$ \\
\hline Mediastinum & $\begin{array}{l}\text { Deviated traclea (1) } \\
\text { Goitre (1) }\end{array}$ & Calcified nodes (1) \\
\hline
\end{tabular}

TABLE II-Radiological abnormalities reported, by age and sex of patient

\begin{tabular}{|c|c|c|c|c|c|c|}
\hline \multirow{2}{*}{$\begin{array}{c}\text { Age } \\
\text { (yrs) }\end{array}$} & \multicolumn{3}{|c|}{ Men } & \multicolumn{3}{|c|}{ Women } \\
\hline & No & Abnormal & $0_{0}$ & No & Abnormal & $\sigma_{0}$ \\
\hline $\begin{aligned} 1-10 & \ldots \\
11-20 & \ldots \\
21-30 & \ldots \\
31-40 & \ldots \\
41-50 & . \\
51-60 & . \\
61-70 & . \\
71-80 & . \\
\geqslant 81 & .\end{aligned}$ & $\begin{array}{r}22 \\
22 \\
17 \\
36 \\
49 \\
67 \\
59 \\
36 \\
7\end{array}$ & $\begin{array}{r}1 \\
2 \\
13 \\
29 \\
29 \\
23 \\
6\end{array}$ & $\begin{array}{r}0 \\
0 \\
6 \\
6 \\
27 \\
43 \\
49 \\
64 \\
86\end{array}$ & $\begin{array}{r}1 \\
21 \\
45 \\
57 \\
70 \\
54 \\
75 \\
40 \\
9\end{array}$ & $\begin{array}{r}1 \\
10 \\
10 \\
19 \\
29 \\
24 \\
5\end{array}$ & $\begin{array}{r}0 \\
0 \\
2 \\
18 \\
14 \\
35 \\
39 \\
60 \\
56\end{array}$ \\
\hline$\overline{\text { Total }}$ & 295 & 103 & 35 & 372 & 98 & 26 \\
\hline
\end{tabular}

The concordance between the radiological findings and the previous clinical history is shown in table III. Radiological changes supported a diagnosis of chronic bronchitis in one out of seven subjects. Four other subjects showed radiological evidence of COAD in the absence of a previous clinical history. In patients giving a definite history of tuberculosis (5), hypertension (14), angina (6), grade III dyspnoea (10), and myocardial infarction (1) the radiological report supported the diagnosis in $1,3,2,2$, and 1 case, respectively. A further six patients were reported as showing radiological changes consistent with the diagnosis of old tuberculosis in the absence of a previous clinical history. Of the patients in table III, $38 \%$ gave a previous history of more than one of the conditions specified. Variation in abnormality rate among 15 reporting radiologists ranged from $5 \%$ (21 films examined) to $29 \%$ (52) for significant abnormalities and from $14 \%$ (23) to $48 \%$ (52) for significant and non-significant combined.

TABLE III-Concordance between clinical history and radiological findings in 152 patients

\begin{tabular}{|c|c|c|c|c|c|}
\hline Condition & & $\begin{array}{l}\text { Positive } \\
\text { history }\end{array}$ & $\begin{array}{c}\% \text { of } \\
\text { sample }\end{array}$ & $\begin{array}{c}\text { Radiographic } \\
\text { changes } \\
\text { support } \\
\text { diagnosis }\end{array}$ & $\begin{array}{l}\text { Radiographic } \\
\text { changes } \\
\text { with no } \\
\text { diagnosis }\end{array}$ \\
\hline $\begin{array}{l}\text { Chronic bronchitis } \\
\text { Old tuberculosis ... } \\
\text { Hypertension } \quad . \\
\text { Angina } \\
\text { Dyspnoea (Grade III) } \\
\text { Myocardial infarct }\end{array}$ & $\begin{array}{l}\cdots \\
\cdots \\
\cdots \\
\cdots\end{array}$ & $\begin{array}{r}7 \\
5 \\
14 \\
6 \\
10 \\
1\end{array}$ & $\begin{array}{l}5 \\
3 \\
9 \\
4 \\
7 \\
1\end{array}$ & $\begin{array}{l}1 \\
1 \\
3 \\
2 \\
2 \\
1\end{array}$ & $\begin{array}{l}4 \\
6\end{array}$ \\
\hline
\end{tabular}

The 667 patients in the study had had a total of 765 chest films taken. Twenty-two per cent of the sample had received chest radiography within the last six months; $38 \%$ within the last year; $56 \%$ within the last three years; and $72^{\circ}$ \% within the last six years. Estimates of the radiation doses received by the study participants during the previous year based on information relating only to radiographs taken at the hospital where the study was undertaken (some patients may have received additional exposure elsewhere) showed that the maximum marrow dose ${ }^{11}$ had been exceeded in $12.5 \%$ of the studv narticipants.

\section{Discussion}

In this study, preoperative chest radiographs performed on people under 30 produced a zero yield. These findings agree with observations made in the USA by Sagel (who studied over 10000 routine chest radiographs) and by Brill (who in 1973 studied routine chest radiographs of 1000 consecutive patients aged up to 18). If in our study patients under 30 had been excluded from the screening procedure the work load on the radiology department in respect of preoperative chest radiography would have been reduced by $16^{\circ} \%$.

In our study $54 \%$ of significant findings were due to cardiomegaly and $19 \%$ to chronic respiratory disease. In the USA Sagel found that $50 \%$ of 951 significant findings were due to cardiomegaly and $32^{\circ}$ oto chronic respiratory disease. Prevalence of cardiomegaly by age in the present study ( $5 \%$ aged $30-49$, $8 \%$ aged $50-59,15 \%$ aged $60-69,27 \%$ aged $70-79$, and $40 \%$ aged 80 years and over) showed a distinct age dependency-an observation which perhaps gives some support to Simon's suggestion ${ }^{12}$ that the diameter of the thorax shrinks with advancing age and hence questions the extent to which asymptomatic cardiomegaly should be regarded as an abnormal finding.

Our findings suggest that clinical examination (including the history) is a more sensitive detector of abnormality than radiological examination for hypertension, angina, grade III dyspnoea, and myocardial infarction, and that radiology is more sensitive for tuberculosis. The findings with regard to chronic respiratory disease are equivocal. The extent to which one is a more sensitive indicator than the other, however, depends on the verdict of an agreed independent validator of the existence of any particular disease. In our study using radiology as the validator of tuberculosis will imply that it is more sensitive than clinical examination; using clinical examination as the agreed validator of hypertension will imply that it is more sensitive than radiology. In the absence of radiological evidence, however, it is well known that clinical opinion may differ concerning the presence in any particular patient of-for example, hypertension or chronic respiratory disease. But the variation between radiologists in their yield of both significant and non-significant abnormalities suggests that here also there is some flexibility concerning the presence or absence of agreed radiological criteria of disease. Flexibility of this order poses a substantial problem for those attempting to estimate the size of the benefit derived from radiology which is independent of that obtained from clinical examination; for the latter often uses the former as an independent validator of the presence of disease. Rationalisation of, for example, preoperative radiology will depend to a large extent on the separation, and then the measurement, of the benefit deriving from each procedure and must therefore wait on future studies of the independent benefits of each.

The problem of the potential immediate and cumulative effects of over-exposure to radiation is vexed. The possibility of gonadal effects has led to the establishment of the "ten day rule" for abdominal radiography, and recently the National Radiation Protection Board set up a two-year study to look into the genetic effect of $x$-rays on the population. In this context the short time interval between chest radiographs observed in the present investigation is a matter of some concern. If, in the absence of chest symptoms, findings on previous chest radiographs taken within the last twelve months had been accepted for preoperative purposes $38 \%$ of the subjects in this study would have been spared further irradiation. It has been suggested ${ }^{13} 6$ that preoperative chest radiographs should be undertaken only in persons with respiratory and cardiovascular symptoms and in those at high risk (such as smokers over 50 and immigrants who have not been examined previously). Such a policy, however, assumes that chest radiography endows its recipients with a substantial benefit which is both independent, and additional to, that derived from clinical examination. If this is so it could perhaps be argued as being unreasonable or possibly even unethical that the opportunity of receiving such benefits be restricted to those who either have recognisable clinical abnormalities or who belong to prescribed high risk groups. 
At present there is insufficient information on either the nature or the magnitude of this "substantial" benefit to allow implementation of a fully rational policy. While the compromise proposed by Brill and others may suffice as a temporary measure, a more permanent decision will have to await the collection of information on, for example, the yield of abnormal findings from common radiological procedures; the yield of abnormal findings within certain high risk categories (such as preoperative chest radiography in the elderly); measurements of the frequency with which the discovery of a positive or negative radiological finding influences subsequent management of the patient; and the degree of additional benefit conferred on the patient by such a change. Given information of this kind, it should be possible to draw up guidelines which will allow a more rational use to be made of the existing diagnostic radiological facilities. Such guidelines are considered as being of great importance by the Royal College of Radiologists, and there are now proposals to establish a National Multicentre Study to collect the necessary information.
AMR's part in the work was done during a student elective attachment to the Department of Community Medicine.

\section{References}

${ }^{1}$ Kerr, I H, British fournal of Anaesthesia, 1974, 46, 558.

2 Ashley, J H H, Pasker, P, and Beresford, J C, Lancet, 1972, 1, 890.

${ }^{3}$ Sagel, S S, et al, New England fournal of Medicine, 1974, 291, 1001.

${ }_{4}^{4}$ Roberts, F, and Schopfner, C E, American fournal of Roentgenology, Radium Therapy and Nuclear Medicine, 1972, 114, 231.

${ }^{5}$ Bull, J W D, and Zilkha, K J, British Medical fournal, 1968, 4, 569.

${ }^{6}$ Brill, P W, Ewing, M L, and Dunn, A H, Paediatrics, 1973, 52, 125.

${ }^{7}$ Kreel, L, et al, British Medical fournal, 1974, 4, 33.

${ }^{8}$ Jones, G R, and Roberts, C J, to be published.

9 Medical Research Council Committee on the Aetiology of Chronic Bronchitis, Lancet, 1975, 1, 775.

10 Rose, G, Blackburn, H, Cardiovascular Survey Methods. Geneva, World Health Organisation, 1968.

${ }^{11}$ Department of Health and Social Security. Code of Practice for the Protection of Persons Against Ionising Radiations arising from Medical and Dental Use. London, HMSO, 1972.

12 Simon, G, Clinical Radiology, 1975, 26, 429.

\title{
Can geriatrics survive?
}

\author{
J C LEONARD
}

British Medical fournal, 1976, 1, 1335-1336

\section{Summary}

Geriatrics has consistently failed to attract enough staff, and hence geriatric units often cannot provide a full service for the elderly. Meanwhile beds in general medical units may be blocked by elderly patients. This division between geriatric and medical units is arbitrary and wasteful. There are no clinical processes or techniques unique to geriatrics, which is probably why the specialty is unattractive; few doctors want to confine their attention only to the elderly. Geriatrics as a separate specialty should therefore be largely abandoned and the care of the elderly reintegrated into general medicine.

\section{Introduction}

The paper by McArdle et $a l^{1}$ on the problem of long-stay patients in acute medical wards has clearly provoked the ire of geriatricians,,$^{23}$ some of whom have suggested that this can best be solved by transferring large numbers of beds from the care of general physicians to that of the geriatricians. The problem that they describe is clearly widespread and causes much illfeeling between medical and geriatric units. In many areas the admission to hospital of elderly patients who fall acutely ill is haphazardly divided between medical and geriatric units. The

University Hospital of South Manchester, Manchester M20 8LR J C LEONARD, MD, FRCP, consultant physician

medical units are usually reasonably well staffed, but there is often reluctance to admit certain elderly patients because of the well-founded fear that large numbers of beds will be blocked for many months at a time. In my own general medical unit about a third of the women inpatients are awaiting transfer, either to chronic sick wards or to accommodation provided for those in need of care and attention under part III of the National Assistance Act 1948. By contrast, geriatric units are often poorly staffed and are consequently often unable to offer a full service to the elderly. The present arrangements seem to me to be arbitrary, inefficient, unsatisfactory, and uneconomic.

One solution, clearly favoured by some geriatricians, is a massive takeover of general medicine by geriatrics. This conveniently ignores the fact that it has proved impossible to staff geriatric units adequately with British-trained doctors. Although it is over 20 years since the first consultant appointments in geriatric medicine were made, the specialty has consistently failed to attract enough junior and senior medical staff. A recent review ${ }^{4}$ stated that $60^{\circ} \%$ of senior registrars in geriatrics are from overseas, and already $30 \%$ of consultants are from overseas. The author comments that "high prospects are apparently not sufficient to attract doctors in this specialty." If, as is generally expected, the supply from overseas declines, geriatrics will face a further severe crisis in manpower.

\section{Structure of medical care}

Brocklehurst maintains that "The principles of geriatric medicine fall into two main groups. First, those of clinical presentation which are unique to the elderly and different from clinical medicine in younger people; second, the structure of medical care which is specifically adapted to the needs of this group." ' ${ }^{5}$ There is, however, no clinical presentation of illness 